\title{
ethics by design, or the ethos of things
}

\section{Cameron Tonkinwise}

full screen print

page 1234567891011121314151617

"Just as the skill of reading animal tracks will not flourish in a metropolitan setting, so calls for the virtues of courage and care will remain inconsequential in a material culture designed to procure comfortable and individualist life.. Putting matters this way is to clarify also what is at the heart of real ethics. It is not finally the desire for greater scholarly circumspection or radicality, but rather the readiness to answer to the claim of eloquent things."

Albert Borgmann :

\section{prelude}

"Now say 'thank you."

"Thaaank yooooou."

"No, come back here! Now say it like you mean it."

There is something painful about the experience of civilizing children into moral beings. This is not because, in the usual romantic sense, it imposes orthopaedic strictures on their 'natural free spirits.' It is rather that their having to be taught how to show the least respect to others, repeatedly and in the most mechanistic fashion, reveals the fragility and artificiality of what we take to be best about human beings. Listening to children poorly ape the mere signifiers of civility, you cannot not have a Nietzchean moment, seeing the extent to which morality is just a bad habit, a well-rehearsed melodramatic script replayed naturalistically night after night.

In many ways, this gap between act and actuality exposed by children whining 'thank you', that one hopes is merely a 'developmental' evil on the way to the good, is the space between morality and ethics. The terms are confused, but I want to follow poststructural conventions (i.e., the interrelated work of Jacques Derrida and Emmanuel Levinas[2] which hold that the former names the codified 'performance criteria' that should evidence the presence of the latter. If ethics represents being just, morality is the culturally and historically specific indicators of such an outcome. In this context, a code of ethics is, if not an outright oxymoron, better called a morality.

When children learning manners do not mean what they say, they are exposing the danger that all educationalists know is associated with explicating assessment criteria: that these indicators can be replicated without the 'way of being' that should inherently, not intentionally, generate such manifestations. The presence of moral conduct does not necessarily mean the presence of ethical being; the former might just be a set of imitated character traits. In fact, given that what actually matters is being ethical, the 
overt presence of moral behaviour is more often than not an indicator of being unethical. (3) At one end of the scale, as Derrida notes in an exegesis of Kant's attempts to find the ethical in the moral, it is not polite to be polite merely in order to be polite. (4) Deliberately reproducing the behaviours outlined in a guide to etiquette is potentially offensive. [5] The point is not to be seen to be, or perhaps even explicitly intend to be, but merely to be, ethical. At the other end of the scale, the hollow performances of too intentionally polite children pain us into the recognition of all those people who, despite following a set of morals to the letter, are nonetheless thoroughly unethical. Institutional religions of all persuasions seem to be particularly good, today no more so than at every moment in our histories, at getting people to conduct themselves according to moral rules so exactly that there are homocidal and even genocidal consequences. In reaction, one is tempted to utterly rule out rule-following when it comes to ethics.

Ethicalness then must only be a way of being, not a knowledge about that way of being. This is the basis of Levinas' Hebraic ethics: do before you know; ethics comes with being always already hostage to the otherness of the other such that you are, before all else, for the other in all you do.[6] The psychoanalytic version of this is Lacan's typically aphoristic formulation, "The status of unconscious is ethical"; [7] understood in reverse fashion, this means that ethicalness is utterly distinct from one's conscious intentions. An intriguing, though very schematic, cross-cultural version is Franciso Varela's Ethical Know-How: 18 Drawing on his connectionist, autopoietic theories about cognition, Varela suggests that ethical expertise is dispositional and enactive; it is the wisdom of the immediate action that is so symbiotic with its environment that it is best characterised as arising through a distributed-self; or better, the no-self of Eastern traditional thinking. In the context of design, Varela's work connects with soft systems, where ethicality is not only the result of the more comprehensive consideration of ends involved in whole systems approaches, but is able to manifest in more unconscious or intuitve ways by being systemic: see for example, Alain Findeli's important essay, 'Ethics, Aesthetics and Design.'[9]

Without pressing the point too far in the direction of these radical (counter)epistemologies - I will return to these toward the end of this article - it might suffice to use the Greek version of these formulae: ethics only ever are as an ethos, an essentially lived culture. As 'lived' rather than professed, ethics only ever appear from the outside; they are what anthropologists (or originally, theorists) [10] call the mores or rituals particularly to the nature of a people. The people themselves do not notice their ethics but quite properly take them for granted. At most, a culture might notice lapses in their ethos, incidents that are improper or foreign to their way of life that must consequently be removed. But otherwise, they are moral without having a morality; which is to say, they interrelate in sustainable ways, in ways that sustain their sociality, rather than risk damaging it in irreparable ways.

If this is the nature of ethics, to be embedded in the very nature of interactions beyond knowing, then a culture that has the notion of ethics consciously at issue, a culture that is trying know what its ethics is or at least codify what it is that would count as being ethical, a culture that can, and needs to, have 'ethics' as the theme for the issue of a journal for example, is in trouble. 
Following the old rule, that if you have to talk about it, you can bet it no longer exists, such a culture must be trying to refind its lost ethos. But this would be profoundly problematic. For, if such a culture could ever come to some agreement about what its ethics was, or should now be, the question would remain, how to convert this morality back into a cultural ethos? How can such a culture move beyond being a collection of so many more or less diligent or recalcitrant children mouthing the words without the requisite feelings? How can it assure that its adults do not more or less naively or cynically do what they know they are supposed to do in ways that nonetheless lead to immoral outcomes? The problem for such a culture is in fact less one of ethics and more one of ethos: irrespective of what coherent ethical system is elaborated, how can it possibly come into being? A lack of ethics qua ethos is essentially a lack of ways of integrating what is known into what is done.

As post-Reformation and post-Enlightenment politicians are fond of saying, the problem of morals is actually a problem of education. If we need to explicate for our children the rules of moral behaviour and then inculcate them into those artificial modes because they can no longer learn to be ethical merely by participating in a culture, if ethics are not learnable in an apprentice-like manner, osmotically through immersion in exemplary behaviour, then we have a very unsustainable society. It is unsustainable not because it is destroying nature, but because it has no nature. Its unsustainability is its lack of an ethics, not because some within it behave unethically. And the absence of the 'naturalised artificial' that is ethics is unsustainable, as without it no authentic moral education can take place to repair such a lacuna.

Aristotle called this learning gap between morals and ethics akrasia: knowing the right thing to do and yet not doing it. [1 1] In terms of ethics as ethos, this situation is impossible: there is only doing right; this is how one knows that one knows what is right; by having done it practically without thinking. Plato also thought this situation was impossible, but for the reverse reason: to fully know is to be compelled to do; to fail to do so evidences a failure to think things through completely, to completion. Heidegger would suggest that Plato's re-emphasis - not doing as knowing, but knowing so doing — opens up the possibility of akrasia - knowing without yet doing. 12) From then on, the space that learning must bridge between knowing and doing what is ethical grows. Learning must occur as acculturation, in Greek paideia, in German Bildung, to form people into the type of subjects who feel the compulsion to act in accordance with what is reasonable.

However, it is apparent, particularly with the crisis of sustainability, that this mythical Romantic project of a formative education has been interrupted. 13$]$ Knowledge of what is right is no longer being accompanied by doing right. It is widely acknowledged for example, that sustainability is a strangely hypocritical politics: even when issues are well understood, actions fail to result; strong and comprehensive awareness of sustainability fails to translate into sustainable behaviour. $[14]$ The icon of modern akrasia is perhaps what UNEP calls the 'Global Consumer', actively concerned about sustainability whilst shopping avidly. 15 Such a bipolar figure is not so much unethical as without ethos, without a way of learning to align their ethics with their life. He or she is small child forever espousing sustainability without the ability to 
transition to being sustainable. And to this extent, our cultures' explicit interest in sustainability is symptomatic of our unsustainability, of the fact that we are culture without the ability to acculturate, a non-culture with an irreparable lack of ethos.

\section{the ethics of things}

There are two things wrong with this rather pessimistic picture of the world's ethics. I will spend most of what follows talking about the first of these, and only toward the end will I turn too briefly to the second.

The first thing wrong with the prelude to this article is its lack of things. Ethics has always been associated with human-to-human relations. Products, artefacts, built environments, communications, have only entered the ethical domain as tangential, and therefore neutral means, used by humans in their relations to other humans. To date, things, designed things, have not assumed a central or at least symmetrical, role with humans when it comes to ethics.

Yet, the cultural perspective adopted on ethics in the preceding account suggests the significance of things. The debates of anthropological discourse have drawn attention to the extent to which cultures comprises not only social relations, but also material relations, shared products and environments that are not only the instruments of social relations or the bearers of symbolic meanings, but also essential aspects of that culture in their own right. A viable ethos is not only sustained by a material culture, but exists in that materiality; an immaterial culture is an impossibility.

In this case, it is crucial to understand the role of the design of things in ethics. Beyond the ethicality of the designer and his or her clients, users and stakeholders, is the ethicality, that is, the materialised ethics, of designed products, environments, and communications themselves. Without taking account of the ethics perpetrated by things, one risks being left, as in the prologue to this article, suspecting that we live in an 'asociety'. While ethics is now a discursive issue for us, and therefore evidently lacking as integral to our human-to-human relations, that we do nonetheless live in some sort of society, with a continued optimism about change by social learning, must mean that there is an ethos somewhere in how we live, a non-discursive sociality that is preserving the possibility of discourse and thereby the transformative regeneration of an ethics.

I am here paraphrasing what Bruno Latour has cleverly called the missing masses.' 16] Theoretical physicists find that the universe is imbalanced when one only takes stock of all the material things in it. They have therefore been forced to theorise that there is a hidden mass somewhere other than in what we currently call matter that holds the universe together. For Latour the converse is true in relation to modern societies. If we only take stock of what we currently understand by 'sociality', it does not add up; our societies should have long since collapsed into irretrievable immorality. There must therefore be an ethical force hidden beyond what we now call 'the social', in other words, in things. 17] Things must be acculturating or ethos-generating. What things design, that is to say, the intentions, actions, understandings and relations that things are designed to design, that they design beyond what 
their designers intended, and that they are redesigned to design by those who use them, must be a vital part of any ethos with a future.

With this in mind, the question is not, 'what can material design learn from the philosophy of ethics?', but, 'what must the philosophy of ethics learn about design and the axial role of designed things in conserving, promoting and altering what is ethical?' Not, 'how can design become ethical?', but, 'how can design be understood as already ethical, as making things ethical?'

\section{rude things}

To access the ethics of or in design, Latour works backwards, starting from things that are unethical, or at least impolite. 18 . He finds an example of a door that rudely will not shut itself after we have moved through, inconveniently remaining an opening when, having served that function, we now have need of a wall once again (for example, to keep the warmth in, a gesture that honours us in the room and dishonours all those outside whose resources we are destroying to keep warm). At a hotel, that bastion of imperial civility, etiquette dictates that there be a doorman, showing respect to those who pass in or out by shutting the door behind them. As Latour points out, this is a clearly moral solution, that is, a particular historico-cultural evaluation of the relevant stakeholders: the value of a door returning to its shut position plus the value of the time and effort of the person passing through the door exceeds the value of the doormen. Such an econo-moral solution is in no way ethical, at least with respect to the doorman's workplace satisfaction, and, in typical fashion, Latour remarks that the original problem returns when the unionised doorman decides to strike for a more rewarding job. It is at this point that the designer is called in. The brief - to devise a mechanism that shuts the door automatically after it is opened - appears neutral enough, though in the context of Latour's tale, the ethico-politico truth is clear - break the strike, render someone unemployed.

The ethicality of the resulting design does not only lie at its origin, withdrawing after the design's implementation, but continues into its uselife as becomes clear when we assess the politeness of the resulting design - let's say a spring, that clever way of capturing the energy of those who open the door so that it can be used to shut the door. For most people, the spring shuts the door politely, efficiently, and reliably. But, depending on the specification of the spring, for some people, the door shuts too quickly (e.g., for those carrying bulky items), for others too slowly (e.g., for those trying to keep a wet wind out), and for others still the door refuses to open, so much effort is required to compress the spring (e.g., for the elderly).

By convention, we judge a design by its functionality, and in these cases would find the spring to be under-optimised. This judgment however is not a particularly strong motivation for undertaking the task of redesigning the spring: maybe someday someone will be interested in the intellectual challenge of enhancing the performance of the spring. What would prompt a quicker redesign is judging the performance of the spring in terms of its human equivalent, the person it made redundant: in other words, if this spring were a doorman, it would be a very rude one, selecting who gets to proceed through and at what rate, and outrightly discriminating against many types of people - children, pregnant women, the infirm, etc. Exposing the immoral 
nature of the spring in this way would motivate the immediate recall of the designer, that expert in making things 'right', that is, morally better.

So we begin to glimpse the ethics in things, the ethos that things enact.

\section{what things know and feel}

A more poetic and less cynical account of the ethics in the design of things is provided by Elaine Scarry's stunning The Body in Pain: The Making and Unmaking of the World. 19. Latour's analyses certainly offer instructive accounts of the ethical nature of things, but, from the point of view of design, Latour's work is not helpful for understanding how things come to be ethical, how ethics manages to be put into designed things. Intriguingly, it is Scarry's interrogations of torture techniques, as exemplars of utterly unethical 'unmaking,' that allow her to understand the making of ethics. Scarry demonstrates, in many ways, that making can only be understood as ethical through and through. What initiates making, and sees making through to the made, and what the actual process of making involves, is ethics.

Her massive argument, violently schematised here, is something like: humans are fundamentally empathetic, so that to acknowledge pain in another is to wish it gone - hence the torturer is fundamentally inhuman; to wish strongly pain were gone for another in a permanent way, covering whenever you can not be there in person for the one in pain, is to dream of a world that would care for the one in pain itself; focusing this dream leads to a projection of some particular thing that could be made that would take that particular pain away. Making is therefore inspired by the ethical desire to enduringly relieve another's pain (or enhance their pleasure), and when successful, the outcome is an ethical thing whose nature and function is relieving pain (or pleasing). In a most beautiful way that I cannot go into here, Scarry also demonstrates how the act of making itself can be understood as essentially the act of being ethical materialised; it is the perception of pain-be-gone objectified, or more exactly, the empathetic 'dance' by which one gets an understanding of another's pain sculptured in space rather than time.

Scarry follows this argument through in numerous ways, but of particular pertinence here is her ability to capture phenomenologically how in everyday life, even non-designers experience and expect things to be moral. When we move through nature and are hurt, tripping on a rock, we are struck by how inert the material world is, how insensitive things are to our fragility, our susceptibility to being hurt by a badly placed rock for example. In reaction, the project of making, of remaking the natural world, replacing it with built environments, is an attempt to make the world more respectful of our human condition. Design is the process of trying to make the world friendlier to us clumsy humans; it is the effort to make the world more caring toward us, more accepting of us and so more morally acceptable to us. Just as Latour sees design as the means for making things less rude, Scarry reveals creation to be the process of investing the world with an emotional intelligence, a knowledge of our feelings. To the non-designer, the surprising pleasure that comes from something well-designed lies with the fact that such an artefact seems to know exactly what it is that we feel; it even seems to know our feelings better than we have ever been able to articulate. 20 At these moments, we are judging the outcomes of human making by how sensitive 
they are to our needs, how attentive they are to what is particular to us. $[21\}$ What we are judging is the extent to which that designed thing has realised this ethicality in how it is, as opposed to its merely appearing to; we are assessing whether it has that empathic quality in its ethos, or whether it is merely reiterating what makes it look like it might be moral.

Scarry's evidence for this materialised ethics by design is the scorn with which we punish designed things when they lapse from this ethos. When a product inadvertently hurts us, our naturalised reaction is to hurt it back. For Scarry, this response is not childish, but evidence of the extent to which we take for granted the ethicality that design puts into the world. We hit the door that pinches our fingers in an attempt to re-sensitise what has suddenly emerged as being inertly insensitive or dumb. A more sophisticated version of this animism is the product liability court case, which attempts to establish how perceptive a product needs to be about the range of uses to which it might be subject: the product that does not manifest as warnings or safety features the awareness of certain scenarios that we believe that 'the average person in the street' would foresee, is expelled from our society (i.e., recalled by the manufacture for disposal), just as any person unfamiliar with our manners is.

\section{things as moral educators}

With this last point, another aspect of design as ethics emerges, one that returns us to Latour. Scarry's products, environments and communications take care of us not only by relieving us of existing pains but also by anticipating possible future pains. If in the process of taking care of us, a product risks harming us in other ways, then, for it to be ethical, for it to be 'forethoughtful', the product must limit our ability to so harm ourselves. In this case, it is not only passively ethical, receiving and thereby taking our pain away, but actively ethical, orienting us away from harm's way. In fact, invariably for a product to do what it is designed to do it must direct us to use it in the particular ways that allow it to do what it is supposed to. It is animate not only in being ethically sensitive to human fragility, but also in interacting with humans, influencing them into the relationship needed for it to be ethically sensitive. Latour refers to these interactions between things and people as hybrids.

For rhetorical reasons, Latour focuses on these more active examples, where things are not merely ethical, but moralising. Since he is arguing that ethics is not merely a matter of and for humans, but a matter that involves a wide continuum of actors from the human to the non-human, he foregrounds cases where non-human things are strong ethical actors. In these situations, humans, rather than convincing each other in human-to-human ways (e.g., an education campaign about the evil consequences of speeding), delegate agency to things through designs that either make easier what should done and more difficult what should not (e.g., speed humps), or do not allow what should not be done and force what should (e.g., an acceleration pedal that disconnects from the engine when one is exceeding the speed limit). Designing then not only inscribes into things a description of human being, but also an ability for things to prescribe to humans how to be. It precisely because the things we vivify by design have this ongoing force that we from time to time get concerned about the controlling of technology. Having 
animated such things to make us ethical, we often find it difficult to halt these golems.

An intriguing extrapolation of Latour's argument about ethical delegation to designed things has recently been developed in the context of sustainability by Jaap Jelsma. 221 Jelsma begins with the recognition that at least a decade of information and education by governments and non-government organisations about more sustainable behaviour, no matter how well researched in terms of behaviour change models, has on the whole failed to lead to significant improvements of the sustainability of developed nations. He notes that the return to the focus of policy initiatives of merely technological solutions - i.e., research into breakthrough technical efficiency gains 23 - is evidence of governments, or at least the EU, giving up on moral education in the face of widespread akrasia. However, rebound effects such as increased volumes and use of more efficientdevices to the point of outstripping the initial per unit efficiency gains, already represent the return of the repressed issue of 'ethos'.

In response, Jelsma takes Latour's descriptions of moral things as a prescriptive design brief. It is not a matter of either behaviour change or built environment/technology change, but behaviour change through built environment/technology change. If the latter can be designed to be ethical in terms of accessibility or safety by dictating appropriate use, why can the latter not also be designed to be a source of ethicality in terms of sustainability? To this end, Jelsma presents a series of examples of devices that 'script' certain types of sustainable behaviour, in this case, water conservation with toilets. The first way of establishing the ethos of ethical water use is by prompting toilet users consciously via a semiotic design strategy - e.g., the dual flush toilet with the two buttons signed in some way. The second influences toilet users in pre-conscious ways via affordances for usability - e.g., the dual flush toilet that assigns the conventional 'press' to the half-flush, requiring you to counter-intuitively 'lift' the button for a full flush, or 'continue to hold down' the button if out of habit you mistakenly press when one in fact you need a full flush. [24] The third influences the toilet users in unconscious ways via system design - e.g., grey and black water recycling systems.

Jelsma recognises that the way these designs design behaviours, moulding users into moral actions, is not deterministic. It less behaviourism, than ecologism in Bateson's sense. It is less a type of planning, than a situated enabling. 25. The scripts are more or less 'open,' only ever making an ethical outcome easier or harder; they are always able to be tactically subverted by the user. In fact, Jelsma recognises that the less open the script, the more likely it is to provoke counter-moral 'work arounds' in reaction to its impolite impositions. Nevertheless, the point is that by embodying certain ethical positions, these sorts of designs educe ethical ways of living - which, as sustained new ways of living, have greater consequence than mere ecoimpact reduction of the production of the product - without the futile didacticism of moralising about sustainability. The ethics in designed things manage to form ethical beings more effectively than any information. By corollary, every designed outcome can be assessed in terms of how ethical it is, that is to say, how effective it is in facilitating and promoting more ethical, or in this case, more water-respecting, ways of being. 
Importantly - and in ways that surpass Latour's analysis - Jelsma's shift into the realm of more designerly applications shows that increased levels of moral devolvement to designed things is not merely a matter of efficiency or expediency. It is not that ethics by design/in designs is just better at educating people to be more ethical than education alone. What is significant is that ethics by design/in designs is more of an ethos. It is not a short-cut but an identity, creating ethical ways of living through the inseparability of material things and the things that are done with them. $(26)$ By being embedded in material culture, in the only ever semi-conscious everyday rituals of making use of designed products, environments and communications, ethics by/in design is the only sustainable form of ethics, the only form of ethics that can sustain itself. If we are dependent upon what we design to live, and what we have designed is ethical, that is, designs ethical ways of being, then we are consequently ethical in how we live, irrespective of whatever platitudes we are trained to mouth.

\section{ethical difficulties}

There are clearly dangers in what Jelsma outlines. To an extent he is embracing the way user-centred design only manages to service the user by unethically caricaturing the user.[28] There are limits to the anthropomorphising of things - they have limited capacity for understanding us, particularly in relation to our habit of changing - and this bites back as reductive projections onto us of who and how we are. Whilst aiming at a dispositional ethics, open yet embedded, a certain instrumentalism risks returning the result to moral conventionalism. Nevertheless, his proactive adoption of Latour's idea of delegated morality, further substantiates Scarry's reading of the designed world as a sustaining source of ethics.

The danger within what Jelsma advocates is in fact a wider danger with the way I have presented ethics as ethos - and here I am mentioning the second omission from my prelude. Ethics becomes a hypocritical or 'akrasiatic' morality, that is to say, it becomes mere displays of the appearance of ethicality rather than being ethical, when it becomes automatic. The child whining 'thank you' has effectively become a machine, a product following the design of a program. In these cases, ethics is being pursued as an explicit intention, a goal in itself, rather than for the other, out of respect for the otherness of the other. For this reason we should be hoping for a more ingrained ethics. However, such an organic ethics itself risks the same automaticity. And when ethics becomes a naturalised artificial, its habitual accomplishment risks being unethical should things change. It does not matter that the ethical is done intuitively, 'without thinking,' so long is it is done; but when situations change, such an unthinking ethics becomes immoral.

The traditional way to avoid this danger is to focus entirely on ethics as thoroughly conscious deliberation. This is for instance what Findeli does to resist the risk of 'technicising' ethical decisions: "the ethical decision always requires total moral engagement on the actor's part... the ethical decision must begin anew for each individual case." 29$]$ I have not dealt with this aspect of ethics at all because, in the context of this paper and its desire to foreground the materialised aspects of design ethics, it is too anthropocentric. What is needed next is an account of such deliberations that involve non- 
human actors, where the prescriptions that things make are given voice as constraints and variables in those ethical conversations

By way of conclusion though, I would like to indicate a different yet related critique of what has been presented here, culminating in Jelsma's 'moralising machines'. For Albert Borgmann, the ethics of designed things lies in the extent to which they foster the best in us. [31] Borgmann calls things that enable and promote activities that require our sustained yet bodily active attention to diversely creative outcomes 'engaging.' [32] He contrasts these with 'disburdening' things, things designed to relieve us of the need for activity or attention by delivering predetermined outcomes. In Borgmann's philosophy of technology, the latter risks reducing us to receptive machines, no longer challenged into being more adept humans. Importantly, this unethical outcome is the result of a zealous designing in Latour's and Scarry's sense. Designers, ethically motivated to take others' pain away, invest things with the sensitivity to intelligently direct humans into use patterns that maximise disburdenment. For Borgmann, the most ethical designer, best attuned to the needs of others, will generate the least ethical outcome, the one that most fully services others needs, thereby disabling them. The more ethical outcome is the thing that is perhaps not the most transparently usable: it is the thing that still involves some pain to use, some work. By being less than completely polite, somewhat drawing attention to itself, its materiality and its design, such a thing would enable ethical ways of being, that is to say, ways of being that remain available for case-by-case deliberation by not withdrawing beneath immediate satisfaction.

Borgmann's perspective prevents the sort of materialised ethics explicated by Latour, Scarry and Jelsma from sliding into an unethical total moral design. But it does so by reasserting the materiality of that ethics, the material resistance such an embodied ethics can have, which therefore preserves our human need to continue to work at being ethical, a labour that no technology can replace.

Cameron Tonkinwise is a Lecturer and Co-ordinator of Design Studies at the University of Technology, Sydney and a member of the Editorial Advisory Board of Design Philosophy Papers.

'The Moral Significance of Material Culture' in A. Feenberg and A. Hannay eds Technology and the Politics of Knowledge Bloomington: Indiana University Press, 1995, 92.

On this nexus, see for example the work of Simon Critchley The Ethics of Deconstruction: Derrida and Levinas Edinburgh: Edinburgh University Press, 1990] 
and John Llewelyn Appositions of Derrida and Levinas Bloomington: Indiana University Press, 2002.

Anne-Marie Willis drew my attention to the ongoing consequences of this habituated morality: that the sign of being ethical becomes more important than being ethical; those who are ethical but not in ways that convention dictates are deemed to be rude and uncivilised even when they are being more ethical than those paying lip service to the mere signs of civility. Tony Fry has long drawn attention to the sheer inability of western bourgeois sensibilities to acknowledge the cultures of care that do sustain other cultures (whether differentiated by ethnicity or class) because those ethics do not manifest as 'manners.'

Jacques Derrida 'Passions: An Oblique Offering' reproduced in On the Name Standford: Stanford University Press, 1995, 8-9.

For the most horrific demonstration of this, see Michael Haneke's thoroughly painful film Funny Games (1997), where two very polite teenagers terrorise a high bourgeois Austrian family, often justifying their violence as retribution for lack of reciprocated politeness.

One of the clearest accounts of this is by Jean-Francois Lyotard: 'Levinas' Logic in A. Benjamin (ed) Lyotard Reader Oxford: Blackwell, 1989. Levinas' most accessible self-summaries are in his interviews, see for example, Ethics and Infinity Pittsburgh: Duquesne University Press, 1985. My paraphrase is obviously inadequate: for example, Levinas insists that being ethical can no longer be understood as a mode of being; it's always prior enactment makes it otherwise than being.

This formulation comes from Lacan's 1964 Seminar The Four Fundamental Concepts of Psychoanalysis Harmondsworth: Penguin, 1979, p34, though it is the subject of the entire 1959-60 Seminar The Ethics of Pyschoanalysis New York: Routledge, 1992. Much work is now being done on the relation between Levinas' and Lacan's understandings of ethics: see for example, S. Harasym Levinas and Lacan: The Missed Encounter Albany: SUNY, 1998 and D. Fryer The Intervention of the Other: Levinas and Lacan on Ethical Subjectivity New York: Other Press, 2004.

8] F. Varela Ethical Know-How: Action, Wisdom, and Cognition Stanford: Stanford University Press, 1999. This book is a translation of 3 short lectures. The ideas mentioned in it are explored in more depth, though with less direct reference to ethics in The Embodied Mind Cambridge: MIT, 1991.

Design Issues, vol.10 no.2 (Summer 1994). Whilst there are moments of 'being ethical without moral knowledge' in Findeli's systems related thinking, he is actually focusing on a more deliberative idea of the ethics of designing, i.e., the non-technical decision making of ethical designing. I will return to this.

Theoria referred originally to the activity of Solonists who would travel to other lands to witness significant rites and then report back on what they had seen, attesting to their having taken place. This account of the etymology of 'theory' is taken from Wlad Godzich by Gregory Ulmer, Heuretics: The Logic of Invention Baltimore: Johns Hopkins University Press, 1994, 120-1. 
Aristotle's discussion of akrasia, traditionally translated as 'incontinence', occurs in Book VII of the Nichomachean Ethicsm 1145a 15-1154b 33: The Complete Works of Aristotle Princeton: Princeton University Press, 1984, Vol 2.

See 'Plato's Doctrine of Truth' in Pathmarks Cambridge: Cambridge University Press, 1998.

See Jean-Luc Nancy 'Myth Interrupted' in The Inoperative Community [Minneapolis: University of Minnesota Press,

194 The fact that project's like Doug McKenzie-Mohr's Fostering Sustainable Behaviour (www.cbsm.com) which translates health behaviour change models to recycling and composting programs, is successful evidences the failure of sustainability 'awareness raising' initiatives to date.

McCann-Erikson conducted some market research for UNEP's sustainable advertising project that was summarised in the 2002 publication, Can Sustainability Sell?, available at: http://www.uneptie.org/pc/sustain/advertising/publications.htm (last accessed 1 July 2004): "It is clear that young people today have strong concerns about the principles that sustainability highlights. These fall into three key areas: the protection of the environment, animal testing and human exploitation in developing countries. With such strong and consistent views from across the globe, why aren't today's youth doing more? One of the main reasons for inactivity is the contradiction in the minds of these consumers. They are both hedonists and idealists They want to 'Have it All': a sustainable planet and their favourite brands. This is the 'use and throw' generation, but at the same time, they have dreams of a private and wonderful world. Most importantly they are not aware of the consequences of their own shopping behaviour. There is a feeling that they are "unable to change the world'. Yet they want the world to change." (10)

Where are the Missing Masses?: The Sociology of a Few Mundane Artifacts' in W. Bijker and J.Law (eds) Shaping Technology /Building Society Cambridge: MIT Press, 1992; also at http://www.ensmp.fr/ latour/articles/1992.html (last accessed 1 July 2004).

17) Ethan Watters makes the analogy between Mark Granovetter's concept of 'weak ties' and 'dark matter' in Urban Tribes New York: Bloomsbury, 2003, however Latour's contribution is to find the missing mass in matter rather than unrecognised social relations.

I am here paraphrasing the first half of 'Where are the Missing Masses?'

19. Oxford: Oxford University Press, 1985. In what follows, I am closely paraphrasing much of the last chapter, 'The Interior Structure of the Artifact'.

[20] Harold Nelson and Eric Stolterman usefully characterise this as 'the expected unexpected' or the 'the surprise of self-recognition' in relation to designed outcomes in The Design Way: intentional change in an unpredictable world Englewood Cliffs, $\mathrm{NJ}$ : Educational Technology Publications, 2003. 
[21] Scarry's strong humanism at times risks essentialising individualism. Whilst on the one hand what is intriguing about designed products are the way they do manage to be perceived by people as 'custom-made' even though 'mass produced', it is important to acknowledge that it is precisely people's inabilities to balance their own individual perceived needs with the wider needs of others, including non-humans, that leads to unsustainability: a device that services my needs perfectly is inevitably going to be unethically unsustainable in the resources it consumes to do so. I will return to the way my paraphrase of Scarry is conflating need fulfilment with ethicalness briefly at the end of this article, but for now I will inadequately point to an ambiguous point in Findeli's 'Ethics, Aesthetics and Design' where he notes that 'an in-depth revision of the notion of "needs" is needed for any more comprehensive ethical system: 57 . To this end, he cites Tomas Maldanodo's genealogy of comfort and Tony Fry's attempts at thinking through a non-essentialist notion of need, neither of which Findeli endorses without saying why.

See 'Innovating for Sustainability: Involving Users, Politics and Technology' in Innovation vol.16 no.2, 2003. Other versions are available online: 'Design of Behaviour Steering Technology', www.ifz.tu-graz.ac.at/sumacad/sa00_jelsma.pdf (last accessed 1 July 2004); and 'Philosophy Meets Design, or How the Masses are Missed (and Revealed Again) in Environmental Policy and Ecodesign', http://www.comp.lancs.ac.uk/sociology/esf/philosophy.htm (last accessed 1 July 2004).

23 As a I write this the Australian Federal Government has announced its decision to divert its funds from greenhouse gas emission abatement strategies - ie programs aimed at reducing output - to greenhouse gas emission sequestration strategies - eg storing liquefied carbon dioxide in fossil fuel aquifers: with regard to the precautionary principle, this scientistic hope that problem can simply be buried is a clear instance of the unethical essence of what is presented as moral action.

24 Jelsma only uses Latourian terminology and so remains at the level of 'product semantics.' I am supplementing his work by introducing Donald Norman's work on 'afforded usability': see The Design of Everyday Things New York: Basic Books, 2002. This second example I give is also not one directly discussed by Jelsma.

251 On this distinction see Lucy Suchman's Plans and Situated Actions Cambridge: Cambridge University Press, 1987.

[26] Perhaps, following Francois Julien's way of translating the Confucian and Daoist notion of shi, a designed ethos is best termed The Propensity of Things [the title of his book: New York, Zone, 1995].

A colleague of Jelsma's takes this point further, still within the context of developing the sustainability of our societies, though with a more sophisticated understanding of the interface between social relations and ritualistic use of appliances: Elizabeth Shove Comfort, Cleanliness and Convenience: The Social Organization of Normality Oxford: Berg, 2003.

Jelsma cites favourably Steven Woolgar's famous critique of the way usability testing is not only about modifying the product, but also about 'enrolling' users: 
'Configuring the User: The Case of Usability Trials' in John Law (ed) A Sociology of Monsters London: Routledge, 1991.

29 'Ethics, Aesthetics and Design', op cit, p62. Most work in this context takes up Aristotle's concept of phronesis: see for example Joseph Dunne Back to the Rough Ground: Practical Judgement and the Lure of Technique [Notre Dame: University of Notre Dame Press, 1993] and Bent Flyvbjerg: Making Social Science Matter. Despite his commitment to deliberation, the point of Findeli's article is to assert a nexus between ethics and aesthetics, one that he finds in "the systemic apprehension of a complex reality [that] arises from intuition [his emphasis]." (63) I am suspicious of this mimetological gesture which appears to return Findeli to an organic technicism, or at least to a somewhat desparate faith in the long lost project of 'aesthetic education'.

[30: This is in fact one of Latour's current projects. Though see Tony Fry's review of his latest book in the previous issue of Design Philosophy Papers

31 I am here paraphrasing Borgmann's 'The Depth of Design' in R. Buchanan and V.Margolin (eds) Discovering Design, though the argument is made more fully in Technology and the Character of Contemporary Life Chicago: University of Chicago Press, 1984.

Mihalyi Czikzentmihalyi calls this zone of challenging creative action, 'flow'. See Flow: The Psychology of Happiness London: Rider, 1992. 